\title{
Hoarding in science, no thanks. Openness and transparency in crisis mode and beyond
}

\author{
Rima-Maria Rahal \& Tobias Heycke
}

This is a translation of a blog post originally posted in German on 04/17/2020 at https://de.in-mind.org/blog/post/ohne-hamstern-in-der-wissenschaft-offenheit-undtransparenz-im-krisenmodus-und-darueber.

During the current SARS-COV-2 pandemic, the scientific approach is ostensibly unable to keep up with the rapid pace at which the crisis is spreading. After developing a research idea, it usually takes years to publish the results. Now, however, things need to move faster. One more reason to embrace open scientifice practices.

The SARS-COV-2 pandemic poses extreme challenges. How can we help those who have been isolated for weeks? Which vaccine can protect us against SARS-COV-2? What about the economy in these times of crisis? When previous research cannot simply be applied to the current circumstances, new and valid insights must be gained quickly. But the wheels of science usually turn slowly - so how can they speed up now?

The changing demands of this crisis call for different research practices. Keeping urgently needed data and insights inaccessible to others, in times of a pandemic, is just as problematic as hoarding rolls of toilet paper at home. Those who do without hoarding help everyone to make it through the crisis. Likewise, only if research data and insights are shared and new research projects are developed collaboratively can new research projects be implemented quickly, joining brainpower across research groups.

To achieve this, researchers need an infrastructure to share research findings and processes. For some years now, research practices have begun to change to facilitate this sharing, moving towards transparency and openness and towards making research content freely available (Open Science). Research in crisis mode can now also benefit from the infrastructure and research practices that have been gradually making their way into everyday scientific life as a result of the Open Science movement.

\section{Open access to knowledge (Open Science)}

To communicate research outputs quickly, many researchers now do not wait for traditional publication channels to process their manuscripts, but rather publish their findings in advance on online servers for scientific papers. More than 1300 pre-published 
articles on Covid-19 and SARS-COV-2 can already be found in the largest collection archives for such pre-publications in biology and medicine. Unlike traditional publication channels, these pre-publications are immediately and freely accessible to all, allowing researchers and the public to inform themselves quickly and freely about current developments. However, this fast pace has its price: unlike publications in scientific journals, pre-publications are not peer-reviewed by experts in the field. Therefore, it is possible that not only high-quality and reliable findings are pre-published, but that some questionable work is made public. Both laypersons and researchers should therefore not blindly rely on these pre-published findings. To facilitate quality checks of the pre-published work, researchers document in detail the methods used and publish them along with the data produced in addition to the pre-published text. Transparently published materials and data also allow others to use the pre-published work as a basis for their own follow-up projects. The published methods and materials can be integrated into new work, adapted, and reused. This idea of sharing methods and data is similar to idea of sharing instructions for homemade respiratory protection masks on the internet. Other people can benefit from the information, implement and improve it. Sewing your own mask of course works better if detailed instructions are freely available, so you do not have to guess the steps necessary from a photo of the finished product. If the instructions were only accessible after a publisher had published them - and only for those who pay to access the instructions - information would spread more slowly, and fewer people would be able to make a mask themselves.

Open practices also concern issues outside of the core area of research. Because many schools have resorted to online teaching, this creates opportunities for teachers to share their teaching concepts with colleagues, provide worksheets for free and at the same time support parents who could neither buy nor create such materials themselves. Implementing online teaching is also a challenge for universities. At the same time, making teaching materials freely available now means that they can also be used by more people than the group of those who would otherwise be in lecture halls. Anyone typing on a private computer while doing home office has to choose between different software solutions. Should we choose commercial products or open source software with free licenses? Researchers also make these decisions. Choosing open source software enables those who cannot afford expensive licenses to reproduce the work of others and to implement their own projects.

The current crisis shows how important it is to do science in an open and transparent way. It also indicates that research needs openness and transparency outside of crisis mode. The crisis gives researchers reasons to change their research practices, which also kindles some hope for science to become more open in general. 


\section{References}

Crüwell, S., van Doorn, J., Etz, A., Makel, M. C., Moshontz, H., Niebaum, J. C., .. Schulte-Mecklenbeck, M. (2018, November 16). 7 Easy Steps to Open Science: An Annotated Reading List. https://doi.org/10.31234/osf.io/cfzyx

Rahal, R.-M., \& Havemann, J. (2019). Wissenschaft in der Krise: Ist Open Science der Ausweg? Forum Wissenschaft. https://doi.org/10.31222/osf.io/3hb6g

UNESCO mobilizes 122 countries to promote open science and reinforced cooperation in the face of COVID-19. (2020, March 30). Retrieved from https://en.unesco.org/news/unescomobilizes-122-countries- promote-open-science-and-reinforced-cooperation-face-covid-19

COVID-19 SARS-CoV-2 preprints from medRxiv and bioRxiv. (2020). Retrieved from https://connect.biorxiv.org/relate/content/181 